where it is most needed, and in which in a number of cases it is not possible to get the equivalent dose of $x$ rays delivered. It is well to use large quantities of radiations as early as possible, and to give a sufficient number of exposures at intervals over a period of, say, two months, and then keep the patient under observation for as long as possible. Watch carefully for evidence of recurrence; when this occurs treat it in the eame way as a primary growth would be dealt with.

In adrocating the use of radium by the surgeon in his operative work, it is clear that two chief points must be realized. He must have a sufficient supply of radium in suitable applicators, and he should know something of the physical properties and action of radium. The principal fields for its use in the hands of the surgeon will be in two types of case:

1. 'The operable case of cancer, where the whole of the tumour can be removed. Ridium is used in this class at the close of the operation as a prophylactic measure. $\mathrm{Mr}$. Sampson Handley is a strong advocate of this method, and he further insists on post-opcrative ray treatment, the com. bination giving the patient the best possible chance of a complete recovery.

2. The inoperable case, in which an operation for the use of the radium is justifiable. In this type of case a large field exists, for the majority of surgically inoperable cases will lrave to be considered from this point of view. The field is a large one, embracing as it does a variety of forms of tumour, and an equally large variety of situations.

It is evident from a consideration of the facts submitted that the possibilities of radium in the treatment of disease have not been nearly exhausted; in fact, up to the present the technique has been more or less experimental. The ex perience of recent years brings forth two dominant facts. 'The potency of radium is now acknowledged by all com. petent workers; it is a most valuable adjunct to the surgeon and the $x$-ray therapist. Indispensable to botb, it is clear that a great future lies before it. To ulilize radium to the utmost it is imperative that much larger quantities must be used than has been customary. Instead of talking in milligrams it will be necessary to think in grams, and to devise techuique which will make it possible to use with safety much larger quantities. 'The larger the quantity used the shorter will be the exposure. This in itself will be an important step, particularly in regions in which the applicrtions are not well tolerated, such as the mouth, pharyux, oesopliagus, rectum, bladder, etc.

The second important point is concerned with the technique of the application. In order to obtain the maximum effect the radium must be accurately applied. The surgeon must be prepared to perform operations for the inscrtion of the radium. In internal regions an exploratory operation may be required to locate accurately the tumour and to place the tubes in position. 'Take, for example, a localized tumour of the pyloric end of the stomach which is incperable. Is it not possible to anchor the tumour in the operation wound insert a number of small tubes into the tumour, allow a few lours for the exposure (and with large quantities of radium used this could be limited to a comparatively short period), remove the radium tubes, and close the wound? Such measures may appcar to be extreme, but is it not a desperate condition which is being dealt with? Surely it is sound practice to give the patient the chance of even a forlorn hope.

The question of radiations versus operation must now be discussed. In all cases, with perhaps one or two exceptions, there can be no doubt that the operative should be the first choicc. In all cases where possible radium should be nsed at the operation, placing it in positions which are likely to contain residual cells. It is surely more logical to endeavour to clieck at the outset any possible residues than to await their development.

The radium exposures should be followed up by thorough $x$-ray treatment. The aim of radium and $x$-ray treatment should be to administer doses of great iutensity in the hope that changes may be brouglit about in the tissues which will lead to the disappearance of any cancer cells.

THE Mayor of Detroit has announced a grant of $1,000,000$ dollars for the purpose of consolidating the Children's Free Hospital and the Michigan Hospital at Framington, to provide additional facilities for the treatment of crippled children in Michigan. Additional contributions to the amount of $5,000,000$ dollars will be made as money is needed for the development of the joint hospital.
THE DIAGNOS'TIC VALUE OF LUMBAR PUNCTURE IN CEREBRAL AND SPINAL HAEMORRHAGES.

BY

WILFRED HARRIS, M.D., F.R.C.P.,

PHYSICIAN FOR DISEASES OF THE NERVOUS SYSTEM, ST. MARY'S

HOSPITAL, $\triangle N D$ TO THE HOSPITAL FOR EPILEPSY AND PaRALYSIS, MAIDA VALE.

For some few years $I$ have realized in increasing degree the extreme diagnostic value of blood mixed with the cerebrospinal fluid remored by lumbar puncture. It is, of course, to be assumed that the lunibar puncture has been cleauly periormed without any great difficulty or prolonged search. ing, as if that happens local haemorrhage due to the pro. longed manipulation of the needle may reach the cerebro-spinal fluid. The blood in such an event is liable to clot easily and is not intimately mixed with the fluid, unless the attempt is renewed on the following or subsequent day, by which time the blood and fluid will be intimately mixed. With this exception, the finding by lumbar puncture of free blood intimately mixed with the cerebro-spinal fluid is a practically certain and invaluable method of rapid differential diagnosis of haemorrhage occurring into the central nervous system, thus distinguishing at once between.apoplexy due to haemorrhage and other causes of cerebral confusion and coma-such as embolism, thrombosis, uraemia, encephalitis, tumour, diabetic coma, epilepsy and general paralysis, disseminated sclerosis, heat-strolse, hysteria, and so on. The one other condition in which blood or its derivative pigments is con. stantly found in the cerebro-spinal flaid is severe concussion with laceration of the brain, and fractured base. '1liere!ore in these two diseases of haemorrhage-either spontaneous, as in apoplexy, or traumatic, due to severe injury-lumbar puncture gives us at once a certain and invariable deciding indication as to whether the lesion is one of haemorihago within the cranial cavity or not. An examination of the chief textbooks on diseases of the nerrous system shows an almost uniform absence of reference to lumbar puncture in the differential diagnosis of apoplexies, though in one or two books devoted to diagnosis the point is mentioned, but not stressed sufficiently.

During the last week $I$ have seen in consultation five cases of acute cerebral apoplexy; in which lumbar puncture showed the cerebro-spinal fluid to be intimately mixed with and opaque with blood. In only tivo of these cases liad cerebral haemorrhage been suggested as the cause of the mental confusion or coma before I saw the patient, uraemia having becn diagnosed in two of tie cases, and encephalitis lethargica in the other.

The listory of the latter case is instructive, inasmuch as the patient lived for fifteen days after the rupture of a small aneurysm on one anterior cerebral artery.

\section{CASE I.}

Miss M., aged 44, had not been feeling well, and had a fainting attack in a 'Turkish bath on March 3rd, but quite recovered. On March 8th she partook of tinned salmon at supper, and was taken acutely ill shortly afterwards with recurrent vomiting and diarrhoea, though other members of the fanily, who had eaten of the same dish, were unaffected. As soon as the sickness began she felt a "flush of bloo:l to the head,"and a sensation of s'eapiness, but was quite conscions, though semi-collapjed when se zu by Dr. Eric Pritchard of Hampstead at 1.30 a.m. The vomiting did not recur, and néxt evening she felt stiffness at tlie baek of the veck and the flushing sensation; being drowsy but able to talk. Even on the third day, during intervals of periols of drowsiness, she would get up fiom the sofa and attend to business, witing cheques and letters, and sos pertectly rationa business, wring cheques and hetters, and was periectly rational, tions. Dr. P'ritchard considered the cass to be one of encephalitis lethargica, and a neurologist w! so sa her with him on the fifth. day confirmed this diagnosis, although he par. lumbar puncture and found the cerebro-spiual fluid y mixed with blood, showing changes in colour and general appearance compatible with a history of four dass in age. I saw her on the eighth day, as during that day she rapidiy became worse, being comatose, with flaccid left hemiplegia, and slight rigidity and muscular twitchings on the right side. 'The case appeared to me as one of undoubted ingravescent cerebral haemorrhage, confirmed by the free blood found in the cerebro-spinal fluid, as I have never seen the slightest trace of blood in the fluid in cases of encephalitis lethargica. Her state made it seem pra. bable that she could not live more than a day or two, yet she lingered another week, with total flaccid paralysis, dying on March 23rd, fifteen days after the initial symptoms of the cerebral haemorrhage. Dr. Spilsbury made a post-mortem examination for Dr. Pritchard and found a ruptured aneurysm, the size of a pea, on the left anterior cerebral artery, one-third of an inch from its 
origin; with considerable haemorrbage-between the membranes. The blood had forced its way between the frontal lobes, damaging considerably both inner fronital convolutions.

CASE II.

In another case, a woman aged 46, the diagnosis of nraemia had been made; becanse the doctor in attendance had treated her previously for high blood pressure and occssionsl albuminuria. She was eight months pregnant, and had been taken suddenly ill when returning home about 6.30 p.m., five hours before I saw her with Dr. Woodcock, of Palmer's Green. She was then quite comatose with slight generalized rigidity, pin-point pupils; and extremely raucous stertorous breathing. The blood pressure was then 160, the knee-jerks brisk, and bilateral extensor plantar reflexes. Lumbar puncture revealed extensive haemorrhage into the cerebro-spinal fluid, which was intimately mixed and quite opaque with bright red blood. Death occurred five hours later, but the diagnosis made of pontine haemorrhage seems probably correct.

Meningeal haemorrhage resulting from fractured base, and lacerations of the brain due to concussion; will in like manner cause bloodstained cerebro-spinal fluid, the depth of stain varying in proportion to the amount of exuded blood. The staining may be no more than a distinct yellow tinge after the lapse of three or four days, as after the third day a pigment derivative from the blood, of the nature of bilo pig. ment, appears in the cerebro-spinal fluid, due to absorption and chemical changes in a localized collection of blood in the membranes or brain substance. This yellow pigment, appear. ing after the third or fourth day of an intrameningeal haemorrhage, was shown many years ago. by Froin to be practically identical with bile pigment, and gives the Gmelin reaction for bile pigment, but does not give the ordinary test for blood. Thus, a small localized cerebral haemorrhage in the neighbourhood of the internal capsnle or other deep area within the brain sabstance, which has neither reached the surface nor ruptured into the lateral or third ventricle, will signalize its presence by the appearance of this yellow stain in the cerebro-spinal fluid within three days, rather than by the appearance of free blood mixing with the cerebro-spinal fluid, as is the case with the larger cerebro-spinal haemorrhages. In fractured base and laceration of the cortex the injury may be sufficient to cause death within a week, and yet the fluid may be stained only a light yellow, with never any free blood mixed with it.

Meningeal venous haemorrhage may occur from the rupture of a vein, usually into the posterior fossa, in periods of intense vascular congestion, as in men during the act of coitus, especially when performed in an abnormal position, such as when standing, and if the man is in poor bealth or suffering from headache at the time. Violent headache and faintness, with, very probably, vomiting, occur at once, and intense headache may persist for several days, though complete recovery is the rule after three or four weeks. Free blood in the cerebro-spinal fluid will be found by lumbar puncture during the first few days, the blood being probably recoverable within half an hour or so of a direct liaemorrháge into the subarachnoid space. - Verous haemorrhages may also occur upon the cortex daring the severe congestion of an epileptic fit, or during the strain of violent coughing, as in whooping-cough, the blood either appearing free and intimately mixed with the cerebro-spinal fluid, or indicating its presence after the third day by the yellow tinge of bile pigment.

Spontaneous haematorrhachis, or intraspinal haemorrhage, may occur as the result of an intense muscular effort, and if the bleeding occurs low down in the spinal canal, amongst the roots of the cauda equina, the blood may clot in situ, and cause pain in the lower extremities, and motor and sensory paresis for years. Such a case I published in 1912 (Proc. Roy. Soc. Med., Neurolog. Sect., February 15th, 1912, p. 115).

When the blood is extravasated higher up in the cerebro spinal axis, then the mixture of blood and cerebro-spinal fluid obtained by lumbar puncture does not clot. Spontaneous haematorrhachis, with the formation of clot around one or more roots of the cauda equina, I believe, accounts for not a few cases of persistent pains in the lower extremities following a heavy muscular effort, such cases being nsually diagnosed as ruptured muscle, fibrositis, or neuritis, and if the pain is in the front of the thigh the condition may be labelled "meralgia paraesthetica." Lumbar puucture would at once decide the diagnosis in such a case, possibly even one or two years after the onset of symptoms, as in the case quoted above, in which I obtained by lumbar puncture a canary-yellow fluid eighteen months after the primary attack. Another example may be given in which the lesion was almost certainly a spontaneous haematorrhachis.

\section{CASE IIr.}

A man, aged 61 , strained his right leg in pushing a heavy iron safe with his knee. Two days later he noticed great tenderness along the front of the thigh, so that he conld not bear the bedclothes over it; the pain then spread to the calf and the sole of the foot, which has ever sinee for the last five rears felt as if he were walking on sand or pebbles. The right foot is always cold and blue; there is no anaesthesia, but a varying degree of hyperaesthesia. The knee-jerks and Achilles jerks are unaffected.

Though lambar puncture was never done in this case, which did not come under my observation until two and a half years after the onset of symptoms, I have no doubt that spontaneous haematorrhachis was the cause, and that lumbar punctare would have shown free blood in the cerebro. spinal fluid in the first few days, and that subsequently tlie fluid would have been yellow-stained, probably for montlus،

\section{SIMPLE GOITRE.}

ROBERT McEARRISON, M.D., D.Sc., LL.D., F.R.C.P., LIEUT.-COLO_EL I.M.S.,

IN CHABGE OF THE DIFICIENCY DISEASTS INQUIRY, INDLAN RESEARCE FUND ASSOCTATION.

IT may be useful at a time when the prevalence of simple goitre in this country is attracting attention to outline our present knowledge with regard to its causation. I include in the term "simple goitre". those sporadic or endemic cases often encountered in towns and country districts in England. Simple goitre is a deficiency disease due to an insufficient supply of iodine for the needs of the thyroid gland, or more properly for the needs of the body cells in the form of the gland's iodine-containing hormone. Two facts may be stated in proof of this definition: (1) Thyroid hyperplasia is readily produced by the use of diets deficient in iodine; (2) iodine in minute doses will prevent and cure goitre when administered at the proper time and season. But while theoretically goitre can, and sometimes does, arise in consequence of a deficient supply of iodine in the food, it arises more commonly in spite of the fact that there is present in the food a sufficiency of iodine. There is abundant proof of this statement; it will suffice, however, to mention in this connexion the results of one fundamental experiment. If animals be confined in dirty cages they will develop goitre spontaneously, the size of the goitre being dependent on the season of the year. and the duration of exposure to the unhygienic conditions. If, however, they be confined in scrupulously clean cages of the same dimensions goitre will not arise. Since the food supply, and therefore the iodine supply, was the same in both cases, it follows that there are factors provided by unhygienic conditions of life, as in dirty animal cages, which render the available iodine in the food insufficient for the needs of the body in these particular circumstances. A sufficiency may become an insufficiency in the presence of such unliygienic conditions. Further, if an additional supply of iodine be provided, or cod-liver oil be administered, goitre will not develop in animals confined in dirty cages. This action of unhygienic conditions of Jife calls to mind the effect of want of sunlight in farouring the development. of rickets when animals are fed on a diet deficient in vitamin $A$, calcium and phosphorus. The parallel must not, however, be pressed too far, for the mode of operation of the two factors-dirt and want of sunlightdiffers; the parallelism is mentioned to emphasizo the imo. portance of such general hygienic conditions of life as cleanly surroundings and sunlight in the maintenance of healtb, an importance which is apt to be minimized in our search for more specific excitants of disease.

This effect of iodine in preventing enlargement of the thyroid gland (goitre) is to some extent exhibited also by free chlorine, although I am not yet certain how far this halogen prevents thyroid hyperplasia. So far as my experiments go they agree in their results with those of Marine who found that iodine prevents both thyroid hyperplasia and goitre; but while chlorine has in some recent experiments prevented tlryroid enlargement, it has not always presented thyroid hyperplasia without enlargement. Two of the facts proved regarding the production of simple goitre may there. fore be stated as follows: (1) That it may arise from an insufficient supply of iodine; and (2) that under unhygienie conditions of life, as represented by dirty animal cages; an additional supply of iodine is-in certain cases especially- 